\title{
Caring for Diversity and Inclusion
}

\section{J. Blake Scott and Lisa Melonçon}

As we were working to send this issue to the publisher, two incidents occurred in disciplinary areas closely related to the rhetoric of health and medicine (RHM). First, four editorial board members of the journal Disability and Society resigned, and over 800 people signed a petition protesting the anti-transgender public statements by the editor of the journal, the petitioners pledging to "not review for, publish with, promote, or subscribe to" the journal until this editor resigns. Around the same time, a number of NCA Distinguished Scholars (66 in the original letter, but a number of these later withdrew their signatures and support) wrote a letter to the organization's Executive Committee objecting to not being consulted about changes this committee made to the Distinguished Scholars selection process-a process that has generated a decidedly non-diverse set of members (prompting the title of the Inside Higher Ed article "When White Scholars Pick White Scholars"). One of these scholars also published an editorial in the journal he edits-Rhetoric \& Public Affairs - further critiquing the new selection process by arguing that it prioritizes "diversity in place of intellectual merit." These objections to long-overdue efforts to ensure better diversity and inclusion in the program generated a wave of counter-responses, including the resignations of $R \mathcal{E} P A$ editorial board members and calls to boycott the journal, statements by NCA caucuses and scholars (including some Distinguished Scholars who signed the original letter of objection), and a letter to the field's leadership signed by "a broad coalition of . . scholars of color, of other marginalized groups, and allies." Among other things, these

(C) 2019 University of Florida Press 


\section{Editors' Introduction}

respondents rejected the specious positioning of diversity and merit as oppositional to each other and the tokenization of underrepresented scholars. This uproar was part of larger movement, which included an earlier petition protesting the lack of diversity in NCA's journal editorships and editorial boards, widely tagged as \#communicationsowhite (from an article empirically documenting this problem) and now \#rhetoricsowhite.

The responses demanding that we do better to ensure diversity and inclusion in our professional forums are important acts of solidarity and commitments to larger structural accountability and improvement. Beyond adding our signatures to petitions/letters, we have worked to make the journal and field of RHM more diverse and inclusive, declaring this commitment but more importantly building it into our practices. At the end of the introduction, we have created a working draft of a journal statement on diversity and inclusion. But performing diversity as a reaction to specific forms or acts of inequity and exclusion is not enough. To this point, we are reminded of Sara Ahmed's (2012) caution in On Being Included that when something is named as a commitment within an institution, the work for that commitment sometimes ceases because it has been named. Ahmed calls this phenomenon the "non-performative," in which the "naming can be a way of not bringing something into effect" (p. 117). Beyond a stated commitment, therefore, we need to engage in the sustained self-evaluation and hard work necessary to ensuring that RHM is a hospitable, edifying, and credible "dwelling place"-a goal we wrote about in our first editors' introduction - and one that welcomes, among others, "related scholars and other health and medical stakeholders that too often comprise only the subjects and imagined audiences of our scholarship."

In the introduction to vol. 1, nos. 3-4 of RHM, we wrote about the process of creating such an inclusive dwelling place through the regular interactions of a community of practice. As we explained drawing on WengerTrayner, such community building involves actively engaging others in imagining our collective. Enabling an interplay between creating identifiable conceptions of the field and imagining "other meanings, other possibilities, other perspectives" (Wenger, 1998, p. 178), we explain, is an important way to "remain open" to new versions of who we are and what we can become. Alignment must be accompanied by imagination, boundary forming must be accompanied by boundary crossing and troubling, and our mutual engagement must both strengthen existing relationships and form new ones. In this 
same introduction, we outlined some of the ways we sought to foster these modes of identification, including through a distributed editorial team, accessible opportunities for publication development, active marketing of the journal's scholarship to various stakeholders, and transparent explanations of the journal's processes. We also expressed our hope that the journal's various submission types will help imagine "the field in extended ways," through, for example, alerting us to new exigencies, encouraging methodological and conceptual experimentation, and facilitating connection-building through dialogues with others.

From its inception, RHM has been a community-based enterprise, formed from and maintained by the many hands of our community of scholars, including our large editorial board and team (including associate, assistant, and guest editors, editorial assistants, and interns) and diverse set of reviewers. Diversity comes in various forms, and as the co-editors of the journal for a newly emergent and changing field, we worked to ensure that our editorial team and board included senior and junior scholars who had been engaged in this work and who represented a range of institutional homes, (inter)disciplinary affiliations, scholarly interests, methodological expertise, and relationships with other health and medical stakeholders. But our community is, and should be, in flux, even as we build on a shared set of concerns and conversations, and RHM should reflect and facilitate more expansive versions of who we are and what we value. Our transparency began with the formation of this team and board and has extended to include documenting and sharing how we operate through video explanations, extensive development work in various forums, the review and decision processes, and other means. Being transparent is important for enabling broader access and engagement and also for remaining accountable to our community, for opening ourselves up to feedback about how we can improve.

We have sought wide feedback about every major decision related to the journal, including our publisher, and we will continue to deliberate with the editorial board and beyond (e.g., with participants at the RHM Symposium) about possible new developments, such as how to develop special issue and featured section topics, how to expand our reviewer pool, how to better market to other stakeholders, how to connect the journal to the Symposium, whether to tie the journal to a professional organization, whether and when to consider open access, etc. In our development work at conferences, open online sessions, and individual conversations, we have tried to 


\section{Editors' Introduction}

encourage a wide range of rhetorically focus scholarship by a diverse range of scholars, and this has resulted in published pieces that have shaped new conversations in the field by authors in various disciplines and at various stages of their careers. As you hopefully have seen in our recent call, we are seeking a new kind of article we call "Ethical Exposure" essays that will extend the field's consideration of ethics in methodological practice in new ways and on different scales. As we state in the call, we hope these pieces will foreground and unpack messy challenges and questions around the "ethical locations, positionalities, disclosures, relationships, engagements, and impacts embedded in our research. We need more discussions of the reflexive negotiations of responding to these quandaries in action." We also recently issued an open call for special topic proposals and, based on evaluations by our editorial board, selected several to begin pursuing in various forms, some as full special issues and some as "featured sections" (or tightly connected clusters of commentaries, persuasion briefs and/or dialogues). Among other topics, we are working with scholars to develop featured sections on decolonial rhetorical methodologies and research involving vulnerable populations in health and medicine. We are also eager to help scholars develop journal manuscripts of rhetorical studies focused on some aspect of LGBTQIA+ health, disability and health, antiracist health, Global South health, and other underrepresented yet hugely important topics in the field. We recognize, and are committed to creating space for, the expansive work driven by the values of diversity, equity, and inclusion in our multi- and interdisciplinary field.

As we mention in the introduction to vol. 1, nos. 3-4, transparency and rigor must be accompanied by care as a defining value of our work: "We value care both in terms of methodological rigor and the care we take in fostering this through our development work and review process." In their special issue on the "Politics of Care in Technoscience," Aryn Martin, Natasha Myers, and Ana Viseu (2015) advocate for a care ethic of "responseability," characterized not by a "prescription" for caring but "a researcher's capacity and willingness to be moved, in both the affective and kinesthetic senses" of this term, toward ameliorative action (p. 11; see Scott \& Gouge, forthcoming, for a fuller discussion of this piece). In this vein, they encourage researchers to "slow care down" and "to expose and to question the self-evidences that would otherwise prescribe its proper objects, as well as its seemingly necessary directions, temporalities, intensities, and forms of 
action" (p. 11). We want to apply this disposition to care to scholarly development, and toward amelioration aimed at creating a more diverse and inclusive dwelling place. Care encourages us to question prescribed forms and means of knowledge-making, to be self-scrutinizing about our positions and enactments of power (including, as Martin, Myers, \& Viseu emphasize, the asymmetrical power dynamics of caring, p. 12), to actively seek and welcome alternative and diverse voices and perspectives, to avoid assumptions about the situations of others, and sometimes to be forgiving of our failings when attempting to do the necessary work of amelioration. "Slowing care down," we think, involves what Krista Ratcliffe (2005) describes as "standing under the discourses of others," which she explains "means first, acknowledging the existence of these discourses; second, listening for (un)conscious presences, absences, unknowns; and third, consciously integrating this information into our world views and decision making” (p. 29). Ratcliffe's methodology of care also involves listening for "identifications across commonalities and differences" (p. 32), a process that is perhaps especially pertinent given the our highly differentiated but also common experiences with health, disease, wellness, illness, living, and dying as scholars and as human beings. We attempted to outline some of our commonalities in the introduction to Methodologies for the Rhetoric of Health E Medicine (Scott \& Meloncon, 2018); we trust that another of our commonalities, as rhetoricians of health and medicine, is that we care.

The inclusive excellence that we want $R H M$ to embody requires transparent and carefully attended-to structures, processes, and practices driven by these values. We know we can and must find additional concrete ways to further center diversity and inclusion, and two of these will be expanding the journal's editorial board and our reviewer pool in order to enable additional diverse perspectives that can expand the field's scholarly work and impact. We will be issuing an open call for new reviewers in the coming weeks, for example, and will be working with the editorial board to recruit such reviewers directly. Inclusivity must also be reflected in the journal's team of editors, and to this end we have articulated from the start of this enterprise our intent to serve as the journal's co-editors for the start-up phase of five years or so but not beyond; this is one reason why we have created opportunities for colleagues, and especially junior scholars, to work closely with us in co-editing special issues. Finally, as the temporary caretakers of our community's journal, we continue to invite your questions, critiques, 


\section{Editors' Introduction}

and feedback about any of the journal's workings on an ongoing basis. This includes, notably, our "rough draft" of the statement of scholarly practice below-something we hope to take up with a number of you at the 2019 RHM Symposium.

\section{Articles in this Issue}

Another reason this issue presents an exigence for extending our commitment to and care of diversity and inclusion is the contributions of its four research articles. Collectively, these articles call for more inclusive research and clinical discourses and practices, including more inclusive accounts of "bottom-up" patient vulnerability and precarity.

In our lead article, "Why Should I Really Consider This? The Rhetoric of Patient Motives in Phase 1 Cancer Clinical Trial Consultations," Richard Marback and Ellen Barton adapt Lauren Berlant's notion of "cruel optimism" to develop and argue for a "more robust account of hope- the interest in trying something - in the consubstantiation of motives when clinicians offer and patients consent to participate in Phase 1 clinical trials." In addition to exposing the limitations of bioethicists' and clinical researchers' notions of "ethical defensible motives" for patients' consent decisions, Marback and Barton explain how patients' desire to try something, even with no prospect of cure for themselves, need not be read as the "undefined hope" of "magical thinking" that Lisa DeTora critiqued in this journal's first issue, but instead as a refusal "to surrender hope." Through their careful analysis and bottom-up theory-building, grounded in an extensive study of patientresearcher conversations around consent, these authors offer a framework for patient recruitment and informed consent consultations guided by "a dialogue with relational integrity" that more fully accounts for a patient's vulnerability (beyond susceptibility) and informed motives.

Next in this issue, Karen Kopelson's 'Dying Virtues: Medical Doctors' Epideictic Rhetoric of How to Die” provides a critical-cultural analysis of five recent and widely influential narratives by physicians instructing us on how to virtuously conduct a "good death." Kopelson explains how these authors' exaltation of "modes of conduct" for undertaking a "courageously" controlled, autonomous, and "self-aware" death makes a number of problematic assumptions about patient agency and virtue. In addition to narrowly positioning the dying patient as an "agentive, self-aware self, master of his or her own destiny — and also master of medical technology," this 
epideictic rhetoric implies that those who don't or can't respond this way are less courageous and less virtuous. Like Marback and Barton, then, Kopelson seeks to make more inclusive our understanding of patient experience in the face of dying. We must identify and "attend to" what gets left out—such as "more varied forms of courage" in dying-by norms about praiseworthy and blameworthy, rational and nonrational conduct around health and medicine.

In "Changing the Face of the Opioid Epidemic: A Generic Rhetorical Analysis of Addiction Obituaries," Kristen L. Cole and Anna F. Carmon shift the issue's focus to representations of those who suffered and died from opioid addiction. In their generic analysis of 73 addiction-related obituaries written by family members or close friends, these authors explain how such encomia "constitute a hybrid rhetorical genre intertwining the conventions of an obituary with a public service announcement," which they call a "public service death announcement (PSDA)." This new, hybrid genre usefully disrupts the "culture of secrecy and shame" around opioid addiction, Cole and Carmon explain, by countering negative stereotypes of drug addicts with praiseworthy qualities, emphasizing the complexity of addiction, and advocating for connecting addicts and their families to broader networks of support. At the same time, in recasting opioid addiction as a "medical affliction that families and communities must work to address and solve," these PSDAs deemphasize political and institutional reforms, including changes to healthcare funding and regulation. Thus, while PSDAs provide an important and new supplement to traditional health PSAs, they could extend their rhetorical power by further blending their appeals with "calls for political intervention and participation." Like the authors of other pieces in this issue, Cole and Carmon advocate for considering additional, overlooked voices in understanding and responding to healthcare crises.

In the final article of this issue, "Surveying Precarious Publics," Christa Teston, Laura Gonzales, Kristin Bivens, and Kelly Whitney offer RHM readers the first of what we hope will be semi-regular pieces that explore some of the practice-level ethical challenges and considerations around conducting research. These researchers discuss their experiences designing and piloting a survey intended to better understand the healthcare concerns, needs, and "senses of self-efficacy" of "precarious publics" around (possible or likely) changes to the Affordable Care Act (ACA) that threaten to limit access. In addition to learning about the risks of people in "precarious positions"- those who identify as "a racial and/or linguistic 


\section{Editors' Introduction}

minority, economically disadvantaged, disabled, former or current drug user, undocumented, un(der)educated, oppressed, sexualized, disenfranchised, criminalized, and/or colonized"-from their own perspectives, Teston, Gonzales, Bivens, and Whitney have the ultimate goal of helping these people better "navigate their individual healthcare challenges," in part by designing "readily spreadable, adaptable media." As the first step, however, these authors offer reflective suggestions for designing surveys of precarious publics, helping other RHM researchers attune "to rhetorical complexities related to survey ethics, inclusion criteria, privacy, stigmatized and misleading language, variations in discursive repertoires, accessibility, and liability." Echoing the adjuration to slow down our research that we cite above (Martin, Myers, \& Viseu, 2015), these authors implore us to "carefully build reciprocal relationships" with (potential) participants in our research design process. Teston, Gonzales, Bivens, and Whitney join Marback and Barton in offering both a conceptual framework and practicelevel suggestions for ethically enrolling patients-at-risk in research practices by creating more inclusive spaces that invite their voices and perspectives.

Considered together, the articles in this issue call for more inclusive ways of recognizing and engaging diverse patient perspectives, ultimately to create more responsive and respectful healthcare practices, and especially for those facing vulnerability, precarity, and risk. They show how the care for which we advocate in publication practices must start with the ways we conduct our research and engage the stakeholders therein.

\section{RHM Statement of Scholarly Practice-DRAFT}

The aspirational statement below is draft or starting point. We ask that you think about and discuss with others what we've attempted to capture here, and that you share your ideas about how to reshape this statement or create an alternative. We will create spaces at the Symposium and in other forums for continued brainstorming and deliberation about this statementincluding about the value of even having a statement as such — and we will find a way to share the collective feedback we receive. In the meantime, please send us any feedback to rhm.journal.editors@gmail.com.

"As a foundational scholarly home of the field by the name same, the Rhetoric of Health E Medicine ( $R H M$ ) is a diverse and inclusive publishing space, qualities that are necessary to creating a forum for rigorous, experimental, 
ameliorative, and applied and useful scholarship. The journal is committed to ensuring multiple types of diversity in its publications, editorial team and board, reviewers, and readers-including but not limited to diversity in identities and experiences, institutional and (inter)disciplinary affiliations, scholarly topics and concerns, methodological approaches, and scholarly forms. $R H M$ 's caretakers work to ensure that the journal is a welcoming and credible dwelling place for the wide range of scholars who work on the rhetorical dimensions of health and medicine, but also actively promote the reimagination and expansion of this community, even while defining it for ourselves and others. The care taken to ensure diversity and inclusion extends beyond the review and publication process to the journal's development and community building work, and to its engagement of other relevant health and medical stakeholders. It requires centering diversity and inclusion not only by declaring them as values but also by concretely and transparently embedding them in the journal's structure, processes, practices, and products. Finally, this care involves remaining attentive and responsive to the ways we fall short of these goals."

\section{References}

Ahmed, Sara. (2012). On being included: Racism and diversity in institutional life. Durham, NC: Duke University Press.

Martin, Aryn, Myers, Natasha, \& Viseu, Ana. (2015). The politics of care in technoscience. Social Studies of Science, 45(5), 1-17.

Ratcliffe, Krista. (2005). Rhetorical listening: Identification, gender, whiteness. Carbondale: Southern Illinois University Press.

Scott, J. Blake, \& Gouge, Catherine. (forthcoming). Theory building in the rhetoric of health and medicine. In Andrea Alden, Kendall Gerdes, Judy Holiday, \& Ryan Skinnell (Eds.), Reinventing (with) theory in rhetoric and writing studies: Essays in honor of Sharon Crowley. Logan: Utah State University Press.

Scott, J. Blake, \& Meloncon, Lisa. (2018). Manifesting methodologies for the rhetoric of health \& medicine. In Lisa Meloncon \& J. Blake Scott (Eds.), Methodologies for the rhetoric of health \& medicine (pp. 1-23). New York: Routledge. 
